\title{
Editorial: Age-specific or Cohort?
}

ARTHUR J. KOVER

Editor
As you CAN SEE, much of this issue is devoted to research among young people and students. Yes, our editorial policy is to reject research among students that purports to be applicable to the general population. But here we are. First, we thought the research in each case was interesting. Second, despite what any of the authors say, the results should not be generalized to the population. Third, we will continue to reject most studentbased research.

This issue raises another, more general issue about people who respond to advertising. To what extent do young people change over time? Does this student research represent a cohort phenomenon; that is, will these people exhibit much of the same behavior as they grow older? Or is this age-specific? As they age, will their behavior and basic needs change greatly (as many advertisers believe)? This is not a trivial question. The socalled baby boomers to some extent are keeping their '60s and '70s values even as many try to shake off the effects of age. True some people in this age group are turning into the troglodytes that one might have expected of aging people. But many are not.

Note the advertising that uses the popular rock tunes of the '60s. Note the popularity of Mick Jagger, whose creaking joints provide a new sort of backup sound for that of his guitar. Note the growth of cosmetic surgery. We are seeing a kind of ossified cohort behavior. So perhaps we might look into these now-young people to see what happens to them as they age.

\section{A BLUSH FROM THE EDITOR}

In the editorial for our first quarterly edition, we promised that issues of the Journal of Advertising Research would be timelier. Well, the issue containing that promise was very late, a result of the creaks and groans of changing a going enterprise. No promises but we expect to be better at on-time performance as we slip into the new groove. JAB 